\title{
What is the economic concept of choice? : An experimental philosophy study
}

\section{Nagatsu, Michiru}

2019-11-01

Nagatsu , M \& Põder , K 2019 , ' What is the economic concept of choice? An experimental philosophy study ' , Economics and Philosophy , vol. 35 , no. 3 , pp. 461-478 . https://doi.org/10.1017/S0266267118

http://hdl.handle.net/10138/325235

https://doi.org/10.1017/S0266267118000500

acceptedVersion

Downloaded from Helda, University of Helsinki institutional repository.

This is an electronic reprint of the original article.

This reprint may differ from the original in pagination and typographic detail.

Please cite the original version. 
https://v2.overleaf.com/project/ 


\title{
What is the economic concept of choice? An experimental philosophy study
}

\author{
April 2018
}

\begin{abstract}
Economists and philosophers disagree about the concept of choice used in economics. Some behavioural economists argue that economic models of choice will improve as they become more and more psychologically realistic. Don Ross argues that this argument fails because its hidden assumption - that the economic concept of choice is the same as the psychological counterpart-is false. Ross conjectures that the economic concept of choice concerns a population-scale pattern of behavioural changes in response to incentives. We conduct a survey experiment to test two predictions that Ross's conjecture generates. The statistical analysis of our data confirms our predictions, although with some qualifications. In interpreting our results, we distinguish two versions of commonsensible realism, strong and weak, and propose the weak one as a plausible explanation of our results. Weak commonsensible realism also produces further testable hypotheses. Some methodological implications of our study are discussed.
\end{abstract}


20

\section{Introduction}

Some behavioural economists argue that economic theory will become better to the extent that it makes its models of choice more psychologically realistic (e.g. Camerer et al. 2005). Don Ross (2011; 2014) argues that this is not necessarily the case because economists' concept of choice is distinct from the one used by psychologists and lay people. This is an intriguing argument; if economists use such a seemingly transparent notion as choice in a systematically different way from psychologists or lay people, this should give the revisionist behavioural economists a pause: how and how much economics can benefit from psychological realism is not so obvious if the economic choice concept does not coincide with the psychological one. Ross's conjecture is based on his first-hand experience as an economist and his conceptual analysis as a philosopher. Given its significant methodological implications, however, his conjecture deserves a more systematic empirical test.

To test Ross's conjecture, we adopt the experimental philosophy (X-phi) approach. Experimental philosophy of science is a relatively new approach that aims to complement philosophers' unsystematic reliance on different evidence bases, such as their intuitions and a small number of case studies of research articles. Specifically, it uses survey-experimental instruments to generate data, in a hypotheses-oriented and controlled fashion, thereby providing a big picture of how scientists understand and use particular concepts (Griffiths and Stotz 2008; Weinberg and Crowley 2009; Nagatsu 2013; Machery 2016). To the best of our knowledge, our study is the first one to explicitly apply the X-phi approach to address conceptual and methodological questions in economics.

We conduct a survey experiment with 127 participants with background in 
various disciplines. We use two vignettes - descriptions of hypothetical scenarios. Vignettes allow to manipulate dimensions related to the notion of choice, one at a time, and ask the participant to report whether he or she considers a scenario an instance of a choice. We use responses in a 7-Likert scale for dependent "choice" variable and collect information about the background characteristics of the participant, such as gender, education, and mother tongue. We use statistical regression analysis - logarithmic regression - to test whether having a disciplinary background in economics has a systematic effect on the "choice" variable. Our analysis supports that economists' concept of choice is distinct from those of noneconomists in two senses: first, a behavioural change is a choice when it is a response to incentive shifts; second, an incentive-induced behavioural change is a choice even if the actor is unaware of the shift in incentives. We find more clear support for the first hypothesis than the second. Our findings contribute empirically as well as conceptually to the debate on economic methodology - How much should economic models become psychologically realistic? Is there any limit?

We proceed as follows: Section 2 contrasts economic and psychological concepts of choice and formulates two empirical hypotheses. Section 3 describes our experimental design, implementation and predictions. Section 4 presents our analysis and results. Section 5 discusses results. We interpret our results and formulate new hypotheses. We also discuss methodological implications of our results. Section 6 concludes. 


\section{Choice concepts: economic vs. psychological}

66 In discussing scientific concepts, it is useful to distinguish two kinds of theses (Grif67 fiths and Stotz 2008). The first kind concerns conceptual variance, the idea that a given concept may have different meanings across different scientific communitiesacross or even within disciplines; the second kind concerns conceptual ecology, the idea that there are often methodological reasons - both epistemic and practicalfor such variance. Ross's (2011) hypothesis concerns both conceptual variance and conceptual ecology, which we will describe in turn below.

Ross (2011) presents his conceptual variance hypothesis in discussing some behavioural economists' claim that "[n]euroscience [...] points to an entirely new set of constructs to underlie economic decision making" (Camerer et al. 2005: 10). Ross points out that what these radical behavioural economists mean by "economic decision making" is a choice in the psychological sense, i.e., behaviour produced by individual internal mental processes. Although cognitive psychology and neuroscience uncover processes radically different from those accessible to lay people's introspections, both notions - research-psychological and folk-psychological-agree that choices are produced by some internal processes. This psychological concept of choice naturally leads the radical behavioural economists to the conclusion that models of economic decision making should be revised according to the latest psychological and neuroscientific research.

In contrast, Ross contends, the practical economic concept of choice has no such connection to the folk counterpart:

In economics a behavioural pattern is chosen just in case it is influenced, through any kind of channel, by incentives. (Ross 2011: 22) 
Three points are important: first, the word "pattern" implies that economic choices are identified through statistical analysis of aggregate data sets; in other words, economic choices are a population-scale phenomenon, not an individual-scale one that can be observed with the naked eye or a brain scanner. Second, the clause 'through any kind of channel' indicates that economic choices are realized on the individual-scale by multiple and heterogeneous causal processes, such as effortful decision making, habits, inertia, automated algorithm, and so on. Consciousness or awareness about these processes is thus not required. Third, nevertheless, economic choices have to be influenced by incentives to count as such.

Ross (2011) also proposes a conceptual ecology hypothesis, which states that these conceptual differences in psychology and economics can be explained - and even justified - by each discipline's distinct epistemic and practical concerns: generally put, psychologists are interested in the process of individual valuation and motivation because that is the scale on which most psychological interventions take effect; in contrast, economists are interested in the population-scale responses to incentive shifts because that is the scale on which most economic interventions operate.

Although it sounds intuitive for philosophers of science who take practical aspects of science seriously, Ross's conceptual ecology hypothesis is a novel and significant claim in the philosophy of economics. Traditionally, methodological issues concerning economic modelling have been discussed in general epistemological frameworks such as idealization and isolation of target systems (see Mäki 2002a: part III) or Weberian ideal types (Angner 2015). These frameworks are however too generic to describe and evaluate subtle methodological differences between economists and psychologists because they both engage in these methods, and 
yet disagree on how to model individual choices in practice. In contrast, Ross's conceptual ecology hypothesis, if true, explains why the disagreement between economists and psychologists - or between mainstream economists and radical behavioural economists-persists.

Before taking conceptual ecology seriously, however, the fact of conceptual variance has to be established-Is the economic concept of choice really different? We focus on this question in the remainder of the paper. Specifically, our study focuses on the differences between economists' and non-economists' concepts of choice. This is a first approximation of Ross's hypothesis that the practical economic concept of choice - particularly the one underlying scepticism towards psychology and neuroscience - is distinct from that held by psychologists and lay people. We do not discuss here whether or how psychological and folk concepts of choice may differ.

We formulate the following two hypotheses from Ross's conceptual variance thesis:

Hypothesis 1: Economists are more likely than non-economists to think of behavioural changes as choices, if they are responses to incentive shifts.

Hypothesis 2: Economists are more likely than non-economists to think of incentivized behavioural changes as choices, even if the actor is not aware that she is responding to incentive shifts.

We leave Ross's third hypothesis - that economic choices are population-scale phenomena - for a future study. Operationalizing the difference between populationscale and individual-scale concepts of choice in an intuitively understandable way is difficult, so we decided to focus on clearly testing Hypotheses 1 and 2. 


\section{Experimental design and implementation}

To test Hypotheses 1 and 2, we implemented an online survey designed to elicit people's intuitive understanding of choice. The approach is called experimental philosophy or X-phi for short; in social sciences this type of surveys are known as quasi-experiments or survey experiments (Nock and Guterbock 2010). In this section, we describe our design and implementation in turn, followed by a summary of two predictions based on Hypotheses 1 and 2 .

\subsection{Design}

In order to elicit and measure the variance in people's intuitive notions of choice, we constructed two vignettes - stylized descriptions of hypothetical scenarios. Vignettes 1 and 2 are designed to test Hypotheses 1 and 2, respectively. Each vignette consists of (i) the common description of the story - $\mathrm{X}$ (the protagonist) does $\mathrm{Y}$ (changes behaviour) - and (ii) the descriptions of several scenarios in which we manipulate one dimension while holding other parts of the story constant. After reading each scenario, the participant was asked whether he or she agreed or disagreed with the statement "X chose to do Y" in a 7-Likert scale-from 1 (strongly disagree) to 7 (strongly agree). In Vignette 1, the dimension concerned the cause of the protagonist's behavioural change. We varied the dimension in 4 levels, corresponding to different causes of behavioural change. In Vignette 2, the dimension concerned the internal process of X's incentivized behavioural change.

Thus we manipulated 2 dimensions, one at a time, in 2 separate vignettes: Vignette 1 is designed to investigate the connection between the notion of choice and types of cause of behavioural change; Vignette 2 was designed to investigate the 
connection between the notion of choice and types of internal processes underlying behavioural change. An alternative design choice would be to use one vignette in which two dimensions are manipulated systematically, e.g., 4-by-3 factorial design. 1 We did not opt for factorial design mainly because some levels in the two dimensions are not independent and create implausible scenarios. 2 In the next two subsections we describe each vignette in more detail. (All scenarios that are not cited below can be found in Appendix 1.)

\subsubsection{Vignette 1: Did Linda choose to eat less meat?}

Vignette 1 is a story about a hypothetical character called Linda, who reduces meat consumption for various reasons in different scenarios. The common introductory part reads as follows:

"In each scenario, our protagonist is Linda. Linda is American, 20 years old, and majors in philosophy. As a student, she lives on a tight budget, supporting her study entirely with a small stipend and with her earnings from a part-time job. She loves to eat all sorts of meat and happily calls herself a carnivore."

Following this description, the participant was shown 4 different scenarios in which 4 different kinds of change trigger Linda's behavioural change, namely (L1) belief

\footnotetext{
${ }^{1}$ Griffiths et al. (2009) for example used 2-by-2-by-2 $=8$ scenarios. In social research it is common to manipulate more dimensions with more levels, generating a vast number of scenarios for even a single vignette. Such design typically requires more subjects and random assignment of these subjects into different subsets of the scenarios because it is practically impossible to expose each participant to more than a certain number of scenarios due to fatigue effects. Factorial surveys with this design are often not driven by clear hypotheses, unlike our case (see Nock and Guterbock 2010: for a review).

${ }^{2}$ See Auspurg and Hinz (2014: 40-42) for the problems of implausible and illogical scenarios and ways to address them.
} 
change: Linda learns about unintended and undesirable environmental and other consequences of meat consumption; (L2) price change: meat prices go up; (L3) medical change: Linda develops some medical condition which makes the digestion of meat difficult; and (L4) nudged change: the cafeterias Linda frequents implement a "nudge", a subtle change of the food display to reduce meat consumption. 3

Central to the test of Hypothesis 1 is scenario L2, in which Linda reduces meat consumption because of price increase, a paradigmatic case of incentive change. L2 reads as follows:

"The meat prices have gone up lately due to the tougher hygiene standards imposed on the meat industry. Because of this substantial price increase, Linda cut down meat consumption to save the cost she spends on food. She still eats meat on some occasions because she loves the taste, but she now eats less than half the amount that she used to."

H1 predicts that economists (defined by their Main Area of Study) are more likely than non-economists to agree with the statement "Linda chose to eat less meat." in L2. We also predict that such a clear contrast is not observed in the other vignettes. This prediction is based on our auxiliary hypothesis that voluntariness is a necessary condition for some behavioural change to count as a choice in vernacular terms. For example, L1 (belief-induced behavioural change) is a clear case of voluntary behavioural change, and the hypothesized economic concept of choice does not interfere with this folk understanding. There should be

\footnotetext{
${ }^{3}$ As mentioned above, these scenarios are naturally correlated with Linda's awareness of the cause. That is, when the cause is belief change it is natural to interpret that she is aware of it. In contrast, when the cause is a nudge it is natural to interpret that she is not aware of it. But crucially, when the cause is a change in prices, she can be aware or unaware of that, and the description is not explicit about this, although it seems more natural to interpret that Linda was aware of the price change.
} 
then no difference between economists' and non-economists' responses to L1. Although it is less clear whether L4 (nudge-induced behavioural change) is a case of voluntary behavioural change, we predict no difference between economists' and non-economists' responses because nudges are originally defined as distinct from incentives (Thaler and Sunstein 2008: 6). If this is the case, then economists' responses will be indistinguishable from those of non-economists, whatever their intuitions are regarding the voluntariness of such behavioural change. We also predict no clear difference between economists' and non-economists' responses to L3 (disease-induced behavioural change). Although Linda can be interpreted as responding to incentives, in the sense that the medical condition increased the subjective cost for Linda to eat meat, we have no evidence to believe that such a specific understanding of what counts as incentives is widely shared among economists.

Another important candidate cause of behavioural change, namely a change in preferences, is not used. We simply kept Linda's preference for meat as exogenously given across all scenarios. Specifically, in all scenarios it is stated that Linda "still eats meat on some occasions because she loves the taste". We opted for this design because we did not want to introduce preferences as another level without understanding how exactly this concept is understood and related to other causes such as belief change. Philosophers as well as economists disagree on the concept of preferences (Hausman 2012; Ross 2014; Dietrich and List 2016; Angner ming; Guala 2017). Importantly, we are not assuming that preferences are reducible to a matter of taste, but simply that it is possible to bracket the conceptual questions about preferences this way in order to focus on Hypothesis 1 . 


\subsubsection{Vignette 2: Did John choose to stop winking?}

Vignette 2 is a story about another hypothetical character called John, who stops winking at his female secretaries and students through various mental processes. The vignette is borrowed with some modifications from Ross (2011), who refers to Heyman (2009). The common introductory part reads as follows:

"In each scenario, the year is 1978, and our protagonist is John. John is American, 56 years old, and teaches history at a university. As a professor, he is popular among students because of his unpretentious style in teaching, and his colleagues also like him for his open and casual character. John, just like other male professors at that time, would wink at female secretaries and students as a means of communication (mostly) without any sexual intention. In North America in the 70s, however, male-to-female winks began to become unpopular for various reasons, including the rise of awareness about gender-neutrality in workplace. John started to receive a frown of disapproval from his female secretaries and students when he winked at them."

Following this description, the participant was shown 3 different scenarios in which the same kind of change takes place - negative feedback from female secretaries and students for John's winking eventually leads him to stop winking; but 3 different internal processes mediate John's behavioural change, namely (J1) John is unaware of the negative feedback but conditioned by it to wink less often; (J2) John is aware of the negative feedback and wink less often to avoid it; and (J3) John becomes unable to wink due to a medical condition (eye muscle problem). For example, vignette J1 reads as follows: 
"It never occurred to John that winking was the cause of their frowning. Nevertheless, the frowning gradually conditioned him to wink less and less frequently, until he completely stopped winking. These days he does not wink at his secretaries and students any more."

Our main interest is whether John's awareness of the negative feedback is relevant for the participant to judge his behavioural change to be a choice. In all 3 scenarios behavioural change is followed by "a frown of disapproval", the negative feedback that is a kind of a disincentive to wink. Hypothesis 2 predicts that economists are more likely than non-economists to agree with the statement "John chose to stop winking." in J1 (unconscious). We do not expect a similar difference in $\mathrm{J} 2$ (conscious). One might expect it, since $\mathrm{J} 2$ is meant to be analogous to Linda's behavioural change in response to price change (L2). However, the difference is that in $\mathrm{J} 2$ but not in L2, it is explicitly stated that the protagonist was aware of the cause of own behavioural change. This will make salient the voluntary nature of behavioural change, a common-sense element of choice (our auxiliary hypothesis), thereby making it more likely for non-economists to judge that John chose to stop winking. The result will be therefore no significant difference. J3 (medical problem making John incapable of winking) is a clear case of involuntary behavioural change, and the hypothesized economic concept of choice will not interfere with this element, so again there will be no significant difference in responses. 


\subsection{Implementation}

We implemented the survey experiment using Qualtrics (www.qualtrics.com). The link to the survey was disseminated using mailing lists at different universities in five different countries, the UK (University of Reading), Finland (University of Helsinki, Hanken School of Economics), Estonia (Tallinn University of Technology), Italy (University of Milan), and Turkey (Bahcesehir University). The survey was also sent to the students who were enrolled in the course Understanding Economic Models (Fall 2016) at the Department of Political and Economic Studies, the University of Helsinki, before the course had started. We did not give incentives in money or course grade. 185 respondents started, of which 127 completed the survey (completion rate was $69 \%$; mean time for completion was 8 minutes).

Vignettes 1 and 2 were presented in this order, but the order of the scenarios within each vignette was randomized for different participants. The main part of the survey was preceded by Research Informed Consent, graphic questions, including the main area of study, the level of education (BA, MA and $\mathrm{PhD}$ ), mother tongue, gender, as well as a prompt to leave any comments on the survey in free form. The characteristics of the participants are summarized in Table 1. We operationalized "economists" as those who selected "Economics" as the main area of study. "Business and Management" is distinguished from "Economics".

\footnotetext{
${ }^{4}$ The Research Informed Consent explains the purpose, procedures, and benefits of the study, as well as the anonymous and voluntary nature of the survey.
} 
Table 1: Participants' characteristics

\begin{tabular}{ll|lr|lr|ll}
\hline Area of study & & Education & & Language & & Gender & \\
\hline Economics & 73 & BA & 34 & English & 16 & Male & 79 \\
Others & 54 & MA & 25 & Estonian & 16 & Female & 48 \\
& & PhD & 63 & Finnish & 34 & & \\
& & & n/a & 5 & Italian & 23 & \\
& & & Turkish & 17 & & \\
& & & & Others & 21 & & \\
\hline Total & 127 & & 127 & & 127 & & 127
\end{tabular}

\subsection{Predictions}

To summarize, we have two predictions:

Prediction 1: other things being equal, economists are more likely than noneconomists to agree to the statement "Linda chose to eat less meat." in L2 but not in L1, L3 and L4.

Prediction 2: other things being equal, economists are more likely than noneconomists to agree to the statement "John chose to stop winking." in J1 but not in J2 and J3.

\section{Analysis and results}

We first present descriptive statistics of the responses from two groups, Economists (Area of study $=$ Economics) and Others (Area of study $=$ other than Economics)

in Table 2. This table also presents the results of two statistical tests, a two-sample t-test with equal variances and a two-sample Wilcoxon rank-sum (Mann-Whitney) 
Table 2: Descriptive statistics of participants' responses

\begin{tabular}{c|c|c|c|c|c|c|c|c|c|c} 
& \multicolumn{9}{|c}{ Economists } & \multicolumn{1}{c}{ Others } \\
& mean & s.d. & $\min$ & $\max$ & $\operatorname{mean}$ & s.d. & $\min$ & $\max$ & $\mathrm{p}$ (t-test) & $\mathrm{p}(\mathrm{WRS})$ \\
\hline L1 & 6.55 & 0.91 & 3 & 7 & 6.33 & 1.10 & 1 & 7 & 0.116 & 0.077 \\
L2 & 5.56 & 1.63 & 1 & 7 & 4.60 & 1.84 & 1 & 7 & 0.001 & 0.001 \\
L3 & 5.30 & 1.88 & 1 & 7 & 4.68 & 1.92 & 1 & 7 & 0.037 & 0.045 \\
L4 & 4.51 & 2.05 & 1 & 7 & 4.07 & 2.01 & 1 & 7 & 0.119 & 0.227 \\
\hline J1 & 4.42 & 2.01 & 1 & 7 & 3.83 & 1.80 & 1 & 7 & 0.044 & 0.095 \\
J2 & 6.44 & 0.99 & 3 & 7 & 6.09 & 1.15 & 1 & 7 & 0.036 & 0.019 \\
J3 & 1.48 & 0.94 & 1 & 5 & 1.55 & 1.20 & 1 & 7 & 0.655 & 0.824 \\
\hline
\end{tabular}

In both cases (last two columns in Table 2) we report p-values indicating whether there is a significant difference between mean score (or ranked ordered score) of Economists and Others. Null-hypothesis (lack of difference) for each scenario can be accepted with the confidence level in \% indicated by p-value; the lower the p-value, the more probable it is that there are systematic differences between the two groups. Table 2 shows that economists are statistically significantly more likely to agree than others that Linda chose to reduce meat consumption not only in L2 (price change: $\mathrm{p} \approx 0.01$ ), but also in L3 (medical change), though to a less extent $(\mathrm{p}<0.05)$. It also shows that, in Vignette 2, economists are statistically significantly more likely to agree than others that John chose to stop winking in J1 (unconscious: $\mathrm{p}<0.10$ ) and even more so in J2 (conscious: $\mathrm{p}<0.05)$.

\subsection{Data analysis}

We want to know whether these more or less statistically significant differences between the responses of the two groups in scenarios L2, L3, J1 and J2 are due to

\footnotetext{
${ }^{5}$ See de Winter and Dodou (2010) for a discussion on the differences between these tests in relation to Likert-scale data.
} 
participants being economists and not other reasons. Our predictions are that this effect - we call it the economist effect - is observed only in L2 and J1 (from Predictions 1 and 2 respectively). To test our predictions, we estimate the economist effect while controlling for other independent variables (participants' individual characteristics). Our estimation strategy consists of two steps: first, we regress a binary dependent variable ("choice" or "no choice") against a binary dummy variable "Economist" including controlling covariates by using logistic regression; second, we measure the economist effect as Average Marginal Effects (AMEs) in different scenarios. We now explain both steps in turn.

First, we need to define how economist effects will manifest in 7 Likert-scale responses. Although the scale has numbers, the answer is qualitative in nature, i.e., they are not cardinal. Thus we create a binary dependent variable from the responses: "no choice" $=0$ if response is $1,2,3$, or 4 ; "choice" $=1$ if response is 5 , 6 , or 7.6 Since this binary dependent variable is dichotomous and not cardinal, we use a logistic function (sigmoid curve), which fits better to the data than a linear function (straight line).

Estimated coefficients indicate the probabilities that the dependent variable ("choice" $=1$; "no choice" = 0) will take the value of one under certain values of independent variable. A simple logistic regression technique estimates a given binary dependent variable using the latent variable approach, where the outcome

\footnotetext{
${ }^{6}$ We test another model with a different threshold. See Section 4.2 below.

${ }^{7}$ The use of logistic regression is common in the social sciences when outcomes (dependent variables) are represented as binary variables. Examples of such regression designs include research in political behaviour (voting, participation in collective action), policy design (belonging to certain group of benefit take-up) and labour economics (unemployment, education, promotion). Although there are other techniques such as ordered logit or multinominal logit to analyse Likert-scale responses, we opt for a simple logit estimation because these alternatives make interpretation of the results difficult (see Williams 2016).
} 
(y) has an observed effect of an unobserved propensity $\left(y^{*}\right)$. A latent variable model in binary regression takes the following form:

$$
y_{i}^{*}=\alpha+\sum X_{i} \beta_{i}+\epsilon_{i}
$$

$$
y=1 \text { if } y^{*} \geq 0 ; y=0 \text { if } y^{*}<0
$$

where $y_{i}^{*}$ is the unobserved individual propensity, $X_{i}$ is the vector of independent variablebles observed for individual $i, \alpha$ and $\beta$ are parameters, and the errors $\epsilon_{i}$ are unobserved but assumed to be independent of $X_{i}$. Standard logistic distribution has a mean 0 and a fixed variance of $\frac{\pi^{2}}{3} \approx 3.29$. This distribution allows to interpret predictions of the logit as the natural logarithm of the odds of having $y=1$ ("choice") versus $y=0$ ("no choice"). Thus, logistic regression assumes the logit to be linearly related to the independent variables:

$$
\ln \frac{P}{1-P}=\alpha+\sum X_{i} \beta_{i}+\epsilon_{i}
$$

where $\mathrm{P}$ is the probability of the event happening and the ratio indicates log odds ratio ( $\mathrm{LnOR}$ ). To make interpretation easier, logit is often transformed to odds $(\exp (\operatorname{logit}))$ or probabilities $(\exp (\operatorname{logit}) / 1-\exp (\operatorname{logit}))$. Thus, logistic regression produces effect estimates in terms of odd ratios or its log - LnOR. We use this logit estimation technique.

Second, we explain our use of Average Marginal Effects (AMEs). Unlike coefficient estimates in linear regression models, odd-ratio and LnOR inform us about the direction of an effect, but it is not intuitive to take the confidence level and interpret the size of an effect. The interpretation of coefficients in logistic re- 
gression is problematic (Mood 2010) and not analogous to that of ordinary least squares (OLS) or average probability estimates (APEs). To overcome problems of interpretation and other restrictions, we use AMEs following recent methodological suggestions (Mood 2010; Hellevik 2009; Angrist and Pischke 2008; Osborne 2006). 8 AMEs indicate the average effect of a one-unit change in discrete variables, are understandable (percentage unit terms), policy relevant (give the average effect across all observations) and comparable across groups and models. 9 In sum, AMEs give us a measure of the economist effect that is appropriate for our purposes.

\subsection{Results}

After controlling for gender $($ male $=1$; female $=0)$, mother tongue (English $=1$; nonEnglish $=0)$, and education level $(\mathrm{BA}=1 ; \mathrm{MA}=2 ; \mathrm{PhD}=3)$, regressions show statistically significant average marginal effects in L2 (price change) and J1 (unconscious), but not in L3 (medical change) and J2 (conscious). This is consistent with our predictions. In what follows, we therefore focus on these two cases. Table 3 presents AMEs in scenarios L2 and J1.10

${ }^{8} \mathrm{An}$ alternative option is average probability estimates (APEs) which are just OLS coefficients in the case of binary dependent variables, and they can be interpreted in the standard way.

${ }^{9}$ You can complement these with marginal effects at different points in the probability distribution, which give percentage unit effects for those with different probabilities, explicitly acknowledging the non-linearity of the relation.

${ }^{10}$ See Appendix 2 for regression results for the other scenarios. There is no statistically significant difference between Economists and Others in all other scenarios. 
Table 3: Regression: the economist effect as average marginal effects in L2 and J1

\begin{tabular}{l|llll}
\hline Scenario & \multicolumn{2}{l}{ Linda price (L2) } & \multicolumn{2}{l}{ John unconscious (J1) } \\
Average marginal effects & $(1=5,6,7)$ & $(1=6,7)$ & $(1=5,6,7)$ & $(1=6,7)$ \\
\hline Economist & $\mathbf{0 . 2 0 * *}$ & $\mathbf{0 . 2 0}$ & $\mathbf{- 0 . 3}$ & $\mathbf{0 . 1 8 ^ { * }}$ \\
& $(0.008)$ & $(0.019)$ & $(0.77)$ & $(0.03)$ \\
Control variables & & & & \\
gender (male=1) & -0.3 & 0.14 & -0.01 & 0.07 \\
& $(0.74)$ & $(0.095)$ & $(0.9)$ & $(0.4)$ \\
Mother tongue (English=1) & 0.10 & -0.03 & -0.22 & 0.01 \\
& $(0.42)$ & $(0.85)$ & $(0.11)$ & $(0.9)$ \\
Level of education & 0.01 & -0.02 & 0.09 & -0.03 \\
& $(0.76)$ & $(0.65)$ & $(0.065)$ & $(0.6)$ \\
\hline N & 122 & 122 & 122 & 122 \\
Adjusted R-square & 0.05 & 0.05 & 0.03 & 0.06 \\
\hline
\end{tabular}

Standard errors in parentheses, ${ }^{*} \mathrm{p}<0.05,{ }^{*} * \mathrm{p}<0.01, * * * \mathrm{p}<0.00$.

Table 3 also includes AMEs with alternative models to see their sensitivity to how we set the threshold between choice and no-choice in the Likert scale. The models 1 and 3 are permissive, counting 5, 6 and 7 on the Likert scale as the positive answer ( $1=$ choice), while Models 2 and 4 are stringent, counting only 6 and 7 as positive.

Table 3 show that the economist effect in L2 (price change) is about 20\%: being an economist makes it on average $20 \%$ more likely to consider Linda's behavioural change as a choice. All individual controls remain statistically insignificant, and the effect remains the same in both Model 1 and Model 2. In J1 (unconscious), we also find the economist effect of a similar size (18\%), but this effect disappears in Model 3, where we are more permissive in counting responses as positive.

The results confirm our Prediction 1, and Prediction 2 to a lesser extent. Concerning Prediction 1, the economist effect is large (about $20 \%$ average marginal effects), statistically significant $(\mathrm{p}<0.05)$, and robust (Models 1 and 2 agree). Where 
does the economist effect come from? In another regression model, we find a significant interaction effect of studying economics and studying it at the BA level (46\%; $\mathrm{p}<0.05$; standard error 0.22. see Appendix 3).11 This can be interpreted as suggesting either that economics education changes people's concept of choice significantly at an early stage, or that the economist effect is a result of self-selection. That is, those who decide to study economics at a BA level are those who hold such a concept of choice in the first place. Either way, the results clearly support Prediction 1: economists are more likely than non-economists to think of a behavioural change as choice, if it is a response to incentive shifts.

Regarding Prediction 2, The economist effect is large (about 18\% average marginal effects), significant $(\mathrm{p}<0.05)$, but not robust-Model 4 shows the effect, but Model 3 does not. Since Model 4 takes only 6 and 7 on the 7-Likert scale as positive answers, we can say that the economist effect is discernible only under the assumption that it should be detected as not only a positive but stronger agreement to the statement.12 Thus Prediction 2- that economists are more likely than non-economists to think of an incentivized behavioural change as a choice regardless of subjective awareness - is not as clearly confirmed as Prediction 1 is, although there is some support.

\footnotetext{
${ }^{11}$ For each scenario, we ran 3 models which take levels of education as categorical rather than linear, one of which takes into account interaction effects between being an economist and levels of education.

${ }^{12} \mathrm{Also}$, the economist effect disappears in models that take levels of education as categorical rather than linear. For J1 (unconscious scenario), all 3 models, including one that takes into account interaction effects, show that having an MA level of education makes one 22 to $35 \%$ more likely to answer positively, regardless of the main area of study (the regression table is not included). We cannot provide a sensible interpretation of this result.
} 


\section{Discussion}

Overall, our results more or less confirm both Predictions 1 and 2, which support Hypotheses 1 and 2, respectively. However, sceptics might argue that the economist effects we observed are mere artefacts of our survey instruments rather than true reflections of the practical economic concept of choice. Those participants with a background in economics may not have responded qua economists but instead manifested personal opinions uncorrelated with the discipline-specific concept. This general scepticism is undermined by the clear economist effect we observed in scenario L2. Critics can of course raise specific questions about how good different vignettes and scenarios are at eliciting the practical economic concept of choice. For example, Vignette 2 about John may have been simply not a good instrument to elicit economists' practice-based responses, compared to Vignette 1 about Linda. More specifically, a price change in L2 may have cued economists to see it as a case to be understood in terms of their professional concept, while "a frown of disapproval" in J1 may have failed to achieve the same effect because it is not an obvious token of disincentives. Notice that this criticism does not lend any support to the general scepticism, though it may explain the different degrees of the economist effects in the two vignettes. Indeed, the fact that one vignette was better than another as an instrument suggests that we are detecting the real effects we are after. The general scepticism explains neither the economist effects nor their variability in different vignettes.

We now turn to discussing specific mechanisms through which our stylized vignettes may have elicited the concept of choice economists apply in their scientific practice. The conjecture we advance is a specific version of commonsensible re- 
alism. Commonsensible realism is the view that the entities and relationships of economic theory are part of the "common-sense furniture of the human world" (Mäki 2002b: 95). In particular, the theory of consumer choice is part of "the ontic furniture of common-sense psychology" (Mäki 2000: 111). Similarly, unobservable entities in economics such as "beliefs, preferences, and the like are venerable. They have been a part of common sense understanding of the world for millennia" (Hausman 1998: 197-198). Although both Mäki and Hausman are talking mostly about unobservables such as beliefs and preferences, it is clear that commonsensible realism applies to observables such as choices.

Unlike this strong version which identifies economic and folk-psychological concepts, our weak version accepts that economic concepts such as choices (as well as subjective beliefs, preferences, and the like) are continuous with commonsense counterparts, but deviate from them in a systematic way. In other words, economists share some common-sense understanding of these concepts, which is overridden or partially modified by scientific disciplinary training (or alternatively purified by self-selective recruitment). While the strong version is not supported by our results, the weak version offers a plausible explanation of how our survey instruments enabled us to observe the economist effects.

The crucial questions are what constitutes the core "commonsensible" part of the choice concept, and what makes economists deviate from it. We hypothesized voluntariness as the key commonsensible: commonsense tells economists as well as non-economists that a choice has to be voluntarily made - otherwise you have no choice! In this sense, Linda's reduced meat consumption induced by price increase (L2) is less of a choice because the tighter budget constraints limited the range of available options, thereby compromising the voluntary nature of her reduced 
meat consumption. According to the standard economic framework, however, a choice is simply a behaviour that satisfies exogenous preferences under certain constraints. In this framework, Linda's reduced meat consumption in L2 is a choice because her behavioural change satisfies her preferences under new sets of budget constraints. This conjecture provides a plausible mechanistic explanation of the economist effect we observed in L2: while non-economists interpreted the increase in prices as reducing the voluntary nature of Linda's response, economists did not because their theory-laden concept of choice told them that it was irrelevant. Some might have explicitly thought: "Linda could have maintained the same level of meat consumption by e.g., buying less clothes."

Our conjectures also generate new hypotheses. On the view of choice as preference satisfaction under constraints, there should be no difference between Linda's consuming less meat because of increased prices (L2), and her consuming more meat because of reduced prices (L2*). Both are choices because both behaviours satisfy preferences under new sets of budget constraints. So economists are expected to consistently see a choice in L2 and L2*, whereas non-economists will tend to see a choice in $\mathrm{L}^{*}$ but not in L2. Also, we can design a better test of H2 - that a behavioural change does not have to be made consciously to count as a choice in the economic sense - by constructing a vignette in which the protagonist's behavioural change is not so obviously involuntary (as in J1's "conditioning" story), while manipulating the dimension of (un)consciousness about the incentive. Since the other scenarios in Vignette 1 (belief change, medical change, and nudged change) did not find any economist effect, we can focus on testing these hypotheses in one vignette in which the incentive shift (price up or down) changes the protagonist's behaviour, where she is (aware or unaware) of this cause. This can 
be done in a 2-by-2 factorial design (price up or down; aware or unaware of it).

We close this section by briefly discussing conceptual ecology and some methodological implications of our findings. Ross's conceptual ecology thesis - that economists' distinctive notion of choice is shaped by their discipline-specific practical concernsis now more plausible, although our empirical support for the conceptual variance thesis alone cannot justify it as a methodological claim. Our results suggest minimally that economic models of choice may not need to be radically re-written by cognitive and neuroscientific discoveries, pace the radical behavioural economists. That is, economists' concept of choice may not be held hostage by psychological findings. How much - and how-psychology and neuroscience can and should change economics is an open methodological question.

This does not mean, of course, that the economic concept of choice will never be influenced by psychological or other findings. On the contrary, since the concept we have been discussing is underpinned by scientific practice, it can change as its use changes in practice. For example, the economist Raj Chetty (2015) explicitly formulates nudges as a legitimate policy lever to influence choices on a par with incentives, contradicting Ross's (2011) assertion that economic choices have to be responses to incentives. The absence of an economist effect in scenario L4-in which Linda reduces meat consumption after a nudge-type intervention-suggests that Chetty's view is not yet common among economists, but this may change over time as a new generation of economists becomes trained in new theories and practices. 13 The changing nature of scientific concepts provides another reason - in addition to conceptual variance - to study economists' practices empirically as the

\footnotetext{
${ }^{13}$ Ross (2014: 304) explains many economists' scepticism towards nudges by liberalism as their political philosophy, but it can be dependent on scientific practice as much as philosophy.
} 
groundwork for a methodological appraisal of economics.

\section{Conclusion}

In this paper, we reported a survey experiment that revealed systematic departures of the economic concept of choice from its folk-psychological counterpart: economists (defined by the main area of study) are more likely than others to interpret the actor's incentivized behavioural change as a 'choice'. We also found some evidence, though somewhat mixed, that economists are more likely than others to interpret the actor's incentivezed behavioural changes as a 'choice' even if he is unaware of the causing incentive shift. In our empirical-conceptual investigation, we proposed voluntariness as the core common-sense dimension of the choice concept, which is influenced by economic practices such as their reliance on incentives. We formulated our proposal as a weak version of commonsensible realism and suggested ways to further investigate how the economic and psychological concepts of choice affect each other. We also suggested that the practical economic concept may change as scientific practices change.

Although our X-phi approach is uncommon in the philosophy of economics, our findings are not isolated. Different qualitative case studies find conceptual variances even within economics (Guala 2011; Hands 2011; Cowen 2004). The main contribution of our survey-experimental study is to offer a less fine-grained but broader view of the conceptual landscape across economics and common-sense psychology. Although incomplete and preliminary, this view suggests a systematic variance between these two terrains. Thus Hausman's (1998: 199) dictum that there is "no principled epistemological divide" between economic and common- 
sense concepts has to be qualified. The divide, though not engraved in stone, can be detected by appropriate instruments. We hope that our results will stimulate more empirical research on how and why economists' concepts differ from those of others, and less defence or criticism of economics based on methodological intuitions. We also hope that our study will help economists articulate the conceptual distinctiveness of their discipline to better communicate their research to noneconomists. Better science communication is, we believe, essential for productive interdisciplinary dialogues and public trust in economic science.

\section{Acknowledgements}

Different versions of this paper have been presented at a KEEL conference on Consciousness and Intention in Economics and Philosophy at Kyoto Sangyo University, 2015, the INEM meeting at the University of Cape Town, 2015, the PSA Biennial Meeting in Atlanta, 2016, and a Helsinki Seminar. We thank the audiences for useful comments, in particular Judith Favereau, Raul Hakli, Jaakko Kuorikoski, Caterina Marchionni, Carlo Martini, Shaun Nichols, Richard Samuels and Julie Zahle. We also thank Francesco Guala, Chiara Lisciandra, Chiara Lombardini, Eduard Machery and Don Ross for valuable suggestions for experimental design. All the remaining mistakes are ours. Michiru Nagatsu received funding from Academy of Finland (No. 294545) to conduct part of this research. Kaire Põder received support from the Methods Lab at Estonian Business School. 


\section{Biographical Information}

Michiru Nagatsu is Associate Professor in Methodologies of Inter- and Transdisciplinary Sustainability Science at Practical Philosophy and the Institute of Sustainability Science, the University of Helsinki. He is the founder of Economics and Philosophy Lab (www.economicsandphilosophylab.org). His current scholarship focuses on empirical philosophy of scientific practices, in particular interdisciplinary model-building in behavioral, environmental and ecological economics.

Kaire Põder is Professor in Economics at the Methods Lab, Estonian Business School. Her research is mostly empirical addressing various issues in applied institutional and education economics. Her recent projects have also concentrated on mechanism design principles in markets, both centralized (e.g., school choice) and decentralized (e.g., labour market).

\section{References}

Angner, E. (2015). To navigate safely in the vast sea of empirical facts. Synthese, 192(11):3557-3575.

Angner, E. (forthcoming). What preferences really are. Philosophy of Science, https://doi.org/10.1086/699193.

Angrist, J. D. and Pischke, J.-S. (2008). Mostly harmless econometrics: An empiricist's companion. Princeton university press.

Auspurg, K. and Hinz, T. (2014). Factorial survey experiments. Sage Publications. Camerer, C., Loewenstein, G., and Prelec, D. (2005). Neuroeconomics: How 
neuroscience can inform economics. Journal of Economic Literature, 43(1):964.

Chetty, R. (2015). Behavioral economics and public policy: A pragmatic perspective. American Economic Review, 105(5):1-33.

Cowen, T. (2004). How do economists think about rationality? In Byron, M., editor, Satisficing and maximizing: Moral theorists on practical reason, chapter 11, pages 213-236. Cambridge University Press.

de Winter, J. C. and Dodou, D. (2010). Five-point likert items: t test versus mann-whitney-wilcoxon. Practical Assessment, Research Éamp; Evaluation, 15(11):1-12.

Dietrich, F. and List, C. (2016). Mentalism versus behaviourism in economics: A philosophy-of-science perspective. Economics and Philosophy, 32(2):249-281.

Griffiths, P. E., Machery, E., and Linquist, S. (2009). The vernacular concept of innateness. Mind and Language, 24(5):605-630.

Griffiths, P. E. and Stotz, K. (2008). Experimental philosophy of science. Philosophy Compass, 3(3):507-521.

Guala, F. (2011). Are preferences for real? choice theory, folk psychology, and the hard case for commonsensible realism. In Kuorikoski, J., Lehtinen, A., and Ylikoski, P., editors, Economics for Real: Uskali Mäki and the Place of Truth in Economic. Routledge.

Guala, F. (2017). Preferences: neither behavioural nor mental. DEMM Working Paper, Number 5.

Hands, W. (2011). Realism, commonsensibles, and economics: The case of contemporary revealed preference theory. In Ylikoski, P., Lehtinen, A., and Kuorikoski, J., editors, Economics for Real: Uskali Mäki and the Place of Truth in Economic. 
Routledge.

Hausman, D. M. (1998). Problems with realism in economics. Economics and Philosophy, 14:185-213.

Hausman, D. M. (2012). Preference, Value, Choice, and Welfare. Cambridge University Press.

Hellevik, O. (2009). Linear versus logistic regression when the dependent variable is a dichotomy. Quality \& Quantity, 43(1):59-74.

Heyman, G. M. (2009). Addiction: A disorder of choice. Harvard University Press.

Machery, E. (2016). Experimental philosophy of science. In Buckwalter, W. and Sytsma, J., editors, A Companion to Experimental Philosophy, chapter 33, pages 475-490. Wiley.

Mäki, U. (2000). Reclaiming relevant realism. Journal of Economic Methodology, $7(1): 109-125$.

Mäki, U. (2002a). Fact and fiction in economics: models, realism and social construction. Cambridge University Press, Cambridge.

Mäki, U. (2002b). Some nonreasons for nonrealism about economics. In Mäki, U., editor, Fact and fiction in economics: models, realism and social construction, chapter 4, pages 90-104. Cambridge University Press.

Mood, C. (2010). Logistic regression: Why we cannot do what we think we can do, and what we can do about it. European Sociological Review, 26(1):67-82.

Nagatsu, M. (2013). Experimental philosophy of economics. Economics and Philosophy, 29(2):263-276.

Nock, S. L. and Guterbock, T. M. (2010). Survey experiments. In Marsden, P. V. and Wright, J. D., editors, Handbook of Survey Research, chapter 28, pages 837-864. Emerald Publishing Group Limited, Bingley, UK, 2nd edition. 
Osborne, J. W. (2006). Bringing balance and technical accuracy to reporting odds ratios and the results of logistic regression analyses. Practical Assessment, Research $\&$ Evaluation, 11(7):1-6.

Ross, D. (2011). Estranged parents and a schizophrenic child: Choice in economics, psychology and neuroeconomics. Journal of Economic Methodology, 18:217-231.

Ross, D. (2014). Philosophy of Economics. Palgrave Macmillan, New York.

Thaler, R. H. and Sunstein, C. R. (2008). Nudge: improving decisions about health, wealth, and happiness. Yale University Press, New Haven.

Weinberg, J. M. and Crowley, S. (2009). The x-phi(les): unusual insights into the nature of inquiry. Studies In History and Philosophy of Science, 40:227-232.

Williams, R. (2016). Understanding and interpreting generalized ordered logit models. The Journal of Mathematical Sociology, 40(1):7-20.

\section{Appendices}

\section{Other scenarios}

\subsection{Vignette 1: Linda eats less meat}

L1 One day, Linda's roommate asked her to join a public lecture entitled "The U.S. Food System: Perspectives from Public Health". Linda attended the lecture, where she learned that current U.S. meat production practices not only damage the environment but also increase health risks for workers, communities, and the public in general. After the lecture, she cut down meat consumption to reduce the environmental damage and the public health 
risks. She still eats meat on some occasions because she loves the taste, but she now eats less than half the amount that she used to.

L3 Linda was recently diagnosed with a rare case of digestive disorder, in which the enzymes necessary to digest animal protein are underproduced. Because of this medical condition, she cut down meat consumption to avoid stomach problems. She still eats meat on some occasions because she loves the taste, but she now eats less than half the amount that she used to.

L4 A group of researchers at Linda's university recently launched an on-campus experiment to investigate how the food arrangement in cafeterias affect what students eat. As part of this experiment, the researchers randomly assigned the dormitories and cafeterias on campus into two groups, A and B. In group A, healthy options such as salad and lentil soup were displayed first while unhealthy options such as chicken nuggets and sausages were placed further down the line. In group B, all options were arranged randomly. Linda happened to live in a dormitory and frequented cafeterias that had been assigned to group A. Because of this experiment, her meat consumption was reduced substantially. She still eats meat on some occasions because she loves the taste, but she now eats less than half the amount that she used to.

\subsection{Vignette 2: John stops winking}

J2 It then occurred to John that winking could be the cause of their frowning, and therefore he started to experiment by winking more or less frequently. His suspicion was then confirmed by the observation that the frequency of women's frowning was positively associated with the frequency of his wink- 
ing. So he stopped winking to avoid their frowning. These days he does not wink at his secretaries and students any more.

J3 It never occurred to John that winking was the cause of their frowning. One day, however, he had an accident which damaged his Orbicularis Oculi, the muscles around eyes, and became unable to wink, although he could still reflexively blink to cleanse and wet his eyes. These days he does not wink at his secretaries and students any more.

\section{Average marginal effects of being an economist} on judgement of choice

\begin{tabular}{l|lll|ll}
\hline Scenario & $\mathrm{L} 1$ & $\mathrm{~L} 3$ & $\mathrm{~L} 4$ & $\mathrm{~J} 2$ & $\mathrm{~J} 3$ \\
Average marginal effects & $(1=6,7)$ & $(1=6,7)$ & $(1=6,7)$ & $(1=6,7)$ & $(1=6,7)$ \\
\hline Economist & $\mathbf{- 0 . 0 2}$ & $\mathbf{0 . 1 1}$ & $\mathbf{0 . 0 8}$ & $\mathbf{0 . 0 7}$ & omitted \\
& $(0.05)$ & $(0.09)$ & $(0.09)$ & $(0.07)$ & \\
Control variables & & & & & \\
gender (male=1) & 0.00 & -0.09 & -0.08 & -0.03 & omitted \\
& $(0.05)$ & $(0.09)$ & $(0.09)$ & $(0.07)$ & \\
Mother tongue (English=1) & -0.05 & 0.03 & 0.14 & 0.18 & omitted \\
& $(0.07)$ & $(0.14)$ & $(0.13)$ & $(0.15)$ & \\
Level of education & -0.00 & 0.05 & 0.05 & 0.02 & omitted \\
& $(0.03)$ & $(0.05)$ & $(0.05)$ & $(0.04)$ & \\
\hline $\mathrm{N}$ & 122 & 122 & 122 & 122 & \\
Adjusted R-square & 0.01 & 0.02 & 0.02 & 0.03 & \\
\hline
\end{tabular}

Standard errors in parentheses, ${ }^{*} \mathrm{p}<0.05,{ }^{* *} \mathrm{p}<0.01,{ }^{* * *} \mathrm{p}<0.00$. We omit the models with $1=5,6,7$, which detect no economist effect, either. In Model J3 there are no coefficient estimates because there was no observations of 6 or 7 among the economists. 


\begin{tabular}{l|c}
\hline $\begin{array}{l}\text { Scenario } \\
\text { Average marginal effects }\end{array}$ & $\begin{array}{c}\text { L2: Linda price } \\
(1=5,6,7)\end{array}$ \\
\hline Economist & $\mathbf{0 . 0 8}$ \\
Interaction effect: & \\
Bachelor & $0.46^{*}$ \\
times Economist & $(0.22)$ \\
Control variables & 0.02 \\
gender (male=1) & $(0.08)$ \\
& 0.057 \\
Mother tongue (English $=1)$ & $(0.12)$ \\
& -0.18 \\
Level of education & $(0.11)$ \\
Bachelor & -0.02 \\
& $(0.01)$ \\
Master & 122 \\
& 0.06 \\
\hline N Adjusted R-square & $\mathrm{p}<0.05, * * \mathrm{p}<0.01, * * * \mathrm{p}<0.00$.
\end{tabular}

$3 \quad$ Interaction effects as average marginal effects of being an economist and education level on judgement of choice 